UCB, Speakers bureau: Research grants, and/or consultant fees from: Amgen, Lilly, AstraZeneca, Astellas, UCB, Astrid Fahrleitner-Pammer Speakers bureau: Speaker fees from: Amgen, Alexion, BMS, Lilly, Fresenius, Pedro López-Romero Shareholder of: Eli Lilly and Company, Employee of: Eli Lilly and Company, Fernando Marin Shareholder of: Lilly, Employee of: Lilly

DOI: 10.1136/annrheumdis-2019-eular.808

\section{FRI0468 EFFECTS OF DIFFERENT VITAMIN D SUPPLEMENTATION SCHEMES IN POSTMENOPAUSAL WOMEN}

Stefano Berardi, Addolorata Corrado, Angiola Mele, Cinzia Rotondo, Antonello Trotta, Natalia Mansueto, Francesco Paolo Cantatore. Rheumatology Clinic, Department of Medical and Surgical Science, University of Foggia, Foggia, Italy

Background: Vitamin D exerts different extra-skeletal effects, including a positive effect on muscle function. Circulating levels of the 25 hydroxylated Vitamin D - 25(OH)D - reflect the body Vitamin D reserves; to reach the optimal serum $25(\mathrm{OH}) \mathrm{D}$ threshold, Vitamin D supplementation is often requested. The commonest Vitamin D supplementation is represented by cholecalciferol (D3), but the hydroxylated Vitamin D metabolite calcifediol $(\mathrm{HyD})$ represents a therapeutic alternative.

Objectives: The aim of the study was to evaluate the efficacy of the calficediol supplementation compared to various cholecalciferol administration schedules in increasing the $25(\mathrm{OH})$ vitamin D serum levels and the effects on muscular function in post-menopausal women.

Methods: 60 post-menopausal women aged $\leq 65$ years with low serum $25(\mathrm{OH})$ D levels $(8-24 \mathrm{ng} / \mathrm{ml})$ were included in the study. Recruited patients were randomly assigned to receive oral Vitamin D $1000 \mathrm{UI}$ day according to four different regimens. 1) cholecalciferol (D3) $300.000 \mathrm{UI}$, single oral dose; 2) monthly cholecalciferol $100.000 \mathrm{UI}$ for three consecutive months; 3) weekly cholecalciferol $7000 \mathrm{UI}$; 4) weekly HyD 7000 UI. At baseline and every three months, for 12 months, the following parameters were evaluated: serum levels of 25(OH)D; PTH, calcium, phosphates; at baseline and every 15 days muscular function was evaluated using the Timed Up and Go (TUG) and the Sit to Stand test.

Results: Weekly administration of $\mathrm{HyD}$ induced a significantly faster and greater increase of $25(\mathrm{OH}) \mathrm{D}$ levels, compared to the other treatment groups (at 12 months: $+384 \%$ vs $+145 \%,+220 \%,+248 \%$ in groups 1 , 2,3 , respectively); the increase appeared after 1 month from baseline. D3 $300.000 \mathrm{Ul}$ single dose induces a slower increase of 25(OH)D compared to monthly and weekly supplementation. An increase of muscular strength was observed after 12 months in all supplementation groups, starting from 1 months from baseline, with a greater effect in subjects treated with weekly HyD compared to D3 treated subjects (TUG 6 second vs $7.3,7.7,7.9$ in groups $1,2,3$, respectively; Sit to Stand 16,2 vs $15.4,15.3,15.7$ in groups $1,2,3$ respectively). Overall, the effects on $25(\mathrm{OH}) \mathrm{D}$ levels and on muscular function were greater in subject treated with weekly D3 compared to subject treated with monthly or single dose D3. No differences in PTH, calcium and phosphate serum levels were found between supplementation groups.

Conclusion: Supplementation with calcifediol is more effective and faster compared to cholecalciferol in increasing $25(\mathrm{OH}) \mathrm{D}$ serum levels; further, weekly cholecalciferol is more effective and faster compared to single dose or monthly administration. Increase in circulating levels of 25(OH)D is associated to an improvement of muscular strength.

\section{REFERENCES:}

[1] Bischoff-Ferrari, et al., Oral supplementation with 25(OH)D3 versus Vitamin D3: effects on 25(OH)D levels, lower extremity function, blood pressure, and markers of innate immunity. Journal for bone and mineral Research, Vol. 27, N. 1, January 2012, pp 160-169.

[2] Bischoff - Ferrari, Which vitamin D oral supplement is best for Postmenopausal women? CurrOsteoporos Rep (2012) 10:251-257.

Disclosure of Interests: Stefano Berardi: None declared, Addolorata Corrado: None declared, Angiola Mele: None declared, Cinzia Rotondo: None declared, Antonello Trotta: None declared, Natalia Mansueto: None declared, Francesco Paolo Cantatore Speakers bureau: PFIZER, ROCHE DOI: 10.1136/annrheumdis-2019-eular.4785

\section{FRI0469 \\ CHANGES IN DKK-1, SCLEROSTIN, AND RANKL SERUM LEVELS FOLLOWING DISCONTINUATION OF LONG-TERM DENOSUMAB TREATMENT IN POSTMENOPAUSAL WOMEN}

Giovanni Adami ${ }^{1,2}$, Angelo Fassio ${ }^{1}$, Camilla Benini ${ }^{1}$, Elisabetta Vantaggiato ${ }^{1}$, Kenneth Saag ${ }^{2}$, Alessandro Giollo ${ }^{1}$, Irma Lippolis ${ }^{1}$, Luca Idolazzi', Giovanni Orsolini ${ }^{1}$, Maurizio Rossini ${ }^{1}$, Davide Gatti ${ }^{1} .{ }^{1}$ University of Verona, Rheumatology Unit, Verona, Italy; ${ }^{2}$ University of Alabama at Birmingham, Division of Clinical Immunology and Rheumatology, Birmingham, AL, United States of America

Background: The positive effects of denosumab (DMAb) on bone mineral density (BMD) are quickly reversible after its discontinuation and concerns about the possible increase in vertebral fracture after stopping denosumab have been recently raised. Indeed, a rebound in bone turnover markers have been described after DMAb discontinuation. Dickkopf-1 (Dkk-1), and sclerostin, Wnt inhibitors, are considered master regulators of bone remodeling and directly influence the Receptor Activator of Nuclear factor Kappa B Ligand (RANKL) serum levels.

Objectives: We sought to determine whether the rebound of bone turnover following DMAb discontinuation is associated with dysregulation of the Wnt canonical pathway and/or with the increase in the receptor-activator of nuclear factor-kappa B ligand (RANKL) serum levels in long-term DMAb postmenopausal users.

Methods: The present study included patients $(n=15)$ with postmenopausal osteoporosis to whom DMAb was administered for 78 months and then discontinued. We collected BMD data at DMAb administration month 60 (M60), M84 (6 months after last DMAb administration, coinciding when the next DMAb dose would typically be due), and after discontinuation, 3 and 12 months of follow-up (FU-M3 and FU-M12, respectively). Serum Cterminal telopeptide of type 1 collagen (CTX-I), Dkk-1, and sclerostin were measured at M60, M84, FU-M3, and FU-M12. Serum N-terminal propeptide of type 1 procollagen (PINP) and RANKL were dosed at M60 M84, FU-M3, and FU-12.

Results: We found a significant decrease in the $\mathrm{T}$ - score at all sites at FU-M12, when compared to M84 $(-0.51 \pm 0.91$ at the lumbar spine; $0.72 \pm 0.33$ at the total hip; and $-0.42 \pm 0.27$ at the femoral neck, $\mathrm{p}<0.05$ ). After DMAb discontinuation (M84 vs FU M12), RANKL, CTXand PINP significantly increased $(+0.041 \pm 0.062 \mathrm{ng} / \mathrm{mL} ;+0.846 \pm 0.590$ and $+124.6 \pm 62.72, p<0.05$, respectively), while Dkk-1 and sclerostin significantly decreased $(-10.90 \pm 11.80$ and $-13.00 \pm 10.52 \mathrm{pmol} / \mathrm{L}$, respectively, $\mathrm{p}<0.01$ ) (Figure 1). No changes in $\mathrm{BMD}$ or any of the markers were found between M60 and M84.

Conclusion: RANKL serum levels progressively increased after discontinuation of long-term DMAb while Dkk-1 and sclerostin serum levels decreased. The increase in RANKL serum levels supports the hypothesis of a sudden loss of inhibition of the resting osteoclast line after DMAb clearance, with a hyperactivation of these cells. Our results suggest that the decrease in serum Wnt inhibitors after DMAb suspension might represent a mere feedback response to the increased bone turnover.

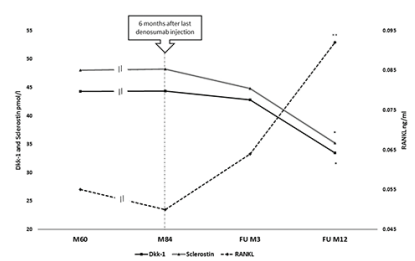

Figure 1. Absolute values of Dickkopf-1 (Dkk-1), sclerostin and Receptor Activator of Nuclear factor Kappa B Ligand (RANKL) following discontinuation. * $\mathrm{p}<0.01$ vs M84; ** $\mathrm{p}<0.05$ vs $\mathrm{M} 84$

Disclosure of Interests: Giovanni Adami: None declared, Angelo Fassio Speakers bureau: Abiogen Pharma, Camilla Benini: None declared, Elisabetta Vantaggiato: None declared, Kenneth Saag Grant/research support from: Amgen, Ironwood/AstraZeneca, Horizon, SOBI, Takeda, Consultant for: Abbvie, Amgen, Ironwood/AstraZeneca, Bayer, Gilead, Horizon, Kowa, Radius, Roche/Genentech, SOBI, Takeda, Teijin, Alessandro Giollo: None declared, Irma Lippolis: None declared, Luca Idolazzi: None declared, Giovanni Orsolini Speakers bureau: Grunenthal, Maurizio Rossini: None declared, Davide Gatti Speakers bureau: Abiogen, Amgen, Janssen-Cilag, Mundipharma, Pfeizer

DOI: 10.1136/annrheumdis-2019-eular.1596 